\title{
ENEOLITICKÁ MEDENÁ INDUSTRIA Z OKOLIA CHTELNICE
}

\author{
Zdeněk Farkaš
}

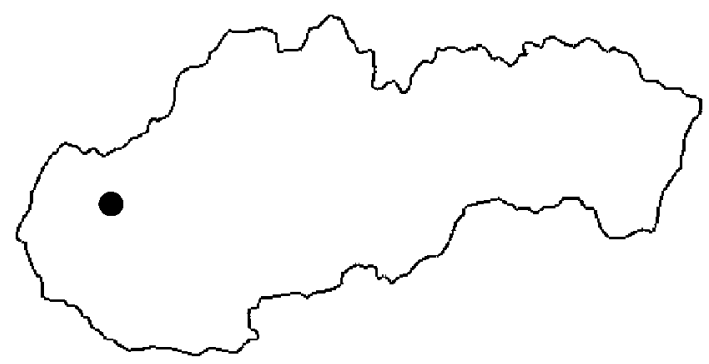

DOI: https://doi.org/10.31577/szausav.2020.67.10

Keywords: western Slovakia, Little Carpathians, Eneolithic, copper industry, copper ingot

\section{Eneolithic copper industry from the vicinity of Chtelnica}

When searching for the context to the accidental find of a copper raw material lump in the Little Carpathians near the village of Chtelnica in western Slovakia, an unexpectedly intense settlement of some local upland sites in the Early and probably also Middle Eneolithc was documented. There is no evidence of fortification at the sites so far. They can be associated with the discovery of nine copper tools - two from a hoard. Intense interest in this area of the Little Carpathians can also be observed in the Late and Final Bronze Age.

Okolo roku 2010 našli pracovníci Štátnych lesov v katastri obce Chtelnica, okr. Piešłany, vel'ký medený ingot neúplného kuželovitého tvaru, údajne sprevádzaný iným, podstatne menším zlomkom medenej suroviny (obr. 1). Kompaktná hruda výtavku s pórovitou štruktúrou a drobnými otvormi si po úniku plynov zachovala vnútorný tvar termického zariadenia s rovným dnom a kónicky dohora sa rozširujúcimi stenami (Farkaš, $v$ tlači).

Nezvyklý tvar hrudy, suroviny, a neznáme okolnosti nálezu neumožňujú jednoznačné časové zaradenie predmetu, hoci väčšina indícií naznačuje jeho mladší, azda postpraveký pôvod.

Prispiet k datovaniu akéhokolvek nálezu, vrátane tohto medeného ingotu môžu aj archeologické nálezy z blízkosti miesta jeho, $v$ tomto prípade iba predpokladaného pôvodného uloženia. Zatial' najznámejšou archeologickou lokalitou v katastri obce Chtelnica je doposial bližšie nedatovaná fortifikácia pri vyústení Chtelnickej doliny, v polohe Vel'ká Čížová (Janšák 1930, 28, 29), ktorú J. Könyöki (1905, 289) označil názvom Pogányvár a $A$. Habovštiak $(1972,4)$ ju zaradil medzi stredoveké hrádky na ostrožni. M. Klčo $(1998,5-12)$ z jej predpolia v Malých Karpatoch uvádza nálezy kamennej industrie a keramiky zo širšieho okruhu lengyelskej kultúry (d’alej $\operatorname{LgK}$ ), azda sčasti ešte zo záveru jej vývoja v období mladého neolitu. Najintenzívnejšie praveké osídlenie Chtelnice sa však zrejme sústredovalo v mierne zvlnenej krajine pozdĺž potoka Chtelničanka, smerom k obci Nižná (Janšák 1935, 46-48), už v priestore Trnavskej pahorkatiny. Medená hruda však bola pôvodne najskôr uložená v zemi v nevel'kej vzdialenosti od miesta nálezu, pravdepodobne v blízkosti alebo priamo na zaoblených vŕškoch Pálenice a Stará Chtelnica v Malých Karpatoch, nad sútokom Chtelničanky a Bukovského potoka (Chtelnická dolina), oddelených výraznou úžlabinou (obr. 1). Starú Chtelnicu, vtedy nezalesnený vŕšok, zaradil medzi archeologické lokality už N. Sándorfi $(1895,282)$ a pripisoval jej predovšetkým strážnu úlohu. V druhej polovici 1. a prvej polovici 2. decénia 21. storočia umožnilo masové rozšírenie detektorov kovov postupné, takmer plošné nepovolené preskúmanie obidvoch víškov spolu so širokým okolím početnými skupinami hladačov. Pracovníkom SNM, Archeologického múzea v Bratislave, sa podarilo pri snahe získat čo najviac údajov o mieste nálezu medeného ingotu aspoň zdokumentovat' z katastrov susediacich obcí Chtelnica, Dolný Lopašov a Dobrá Voda, okr. Pieštany a Trnava, devät medených eneolitických nástrojov (obr. 1; 3). Súčasne získali informácie o dalších, zrejme zberatel'sky a finančne hodnotnejších tu objavených predmetoch, napr. medenej dýke a sekeromlatoch (údajne typu Handlová?), aspoň v jednom prípade uložených do zeme vo forme hromadného nálezu. Pri overovaní miest ich pôvodného uloženia sa predovšetkým na ploche Starej Chtelnice podarilo nájst’ nezasypané hladačské výkopy, ktoré v niektorých prípadoch obsahovali 


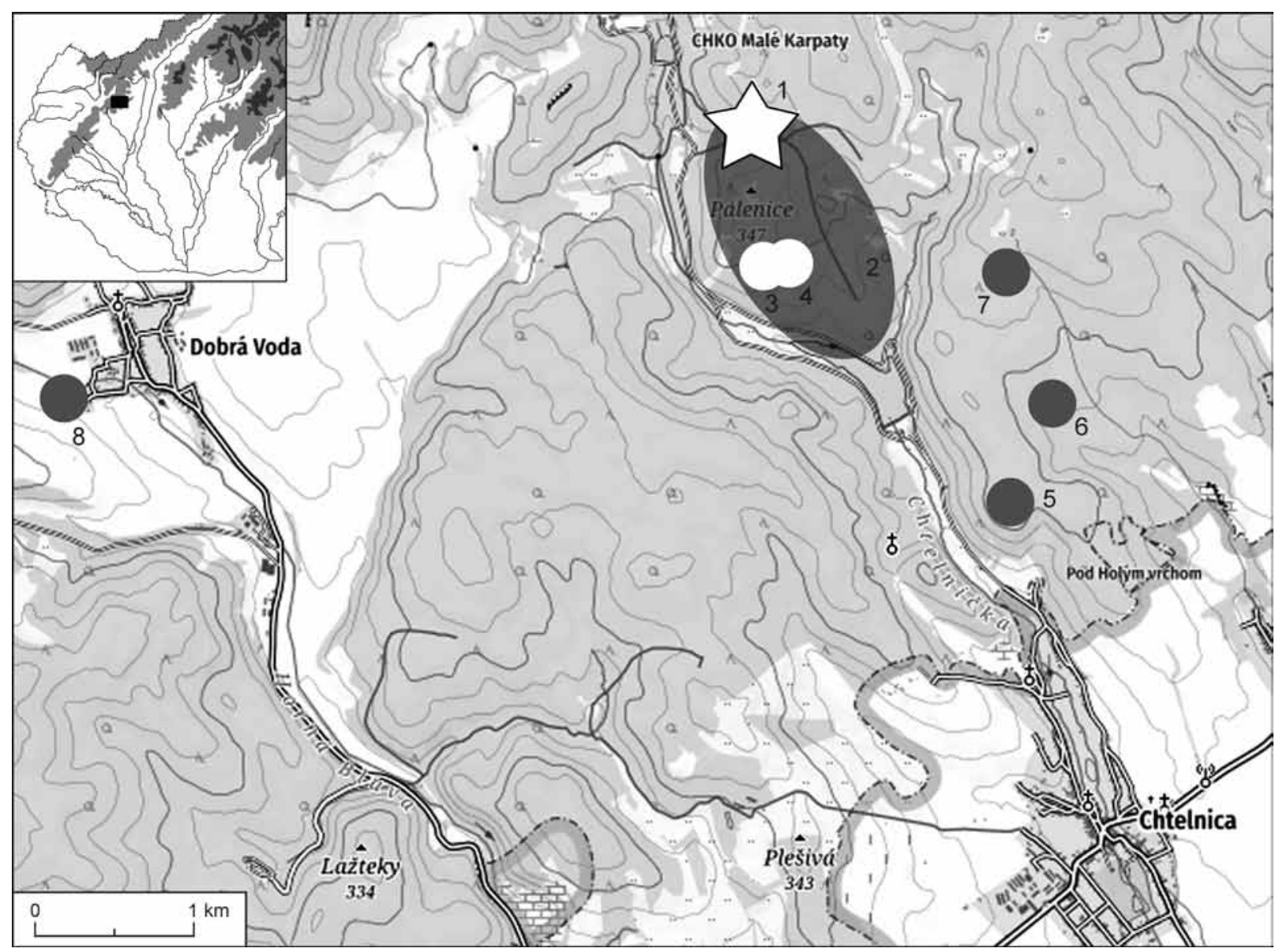

Obr. 1. Mapa Malých Karpát v okolí Chtelnice. 1 - poloha Pálenice, miesto nálezu medeného ingotu; 2 - Stará Chtelnica a Pálenice, predpokladaný rozsah eneolitického osídlenia; 2-8 -miesta nálezov eneolitickej medenej industrie; 2-5 kataster obce Chtelnica; 6, 7 - kataster obce Dolný Lopašov; 8 - obec Dobrá Voda (https://mapy.hiking.sk).

početné zlomky keramiky z obdobia lengyelskej kultúry a miestami aj takmer súvislé plochy prepálenej mazanice. Bez väššieho plošného odkryvu možno len predbežne zaradit čast̉ nálezov už do záveru neolitu, väčšinu však až do obdobia ludanickej skupiny LgK so zretelnými prvkami skupiny Bajč-Retz. Terénna obhliadka tak potvrdila poznatky, získané pri výstavbe Chtelnickej priehrady, kde P. Novák (1984, 161, 162) odkryl zvyšky troch sídliskových objektov zo záveru LgK. Pravdepodobne tak možno predpokladat' pomerne vel'ký rozsah eneolitickej osady rozkladajúcej sa od inundácie pôvodného potoka až po temeno Starej Chtelnice a Pálenice, po obidvoch stranách oddelujúcej ich eróznej ryhy.

\section{OPIS A VYHODNOTENIE NÁLEZOV}

- Priamo z hrany vrcholovej plošiny Pálenice (obr. 1: 3) pochádza mohutný plochý medený klin $\mathrm{s}$ mierne trapézovitým pôdorysom, $\mathrm{s}$ vejárovito rozšíreným oblúkovým ostrím a kolmými bočnými stenami. Hrúbka tela sa mierne zužuje smerom k tylu. Rovné tylo má v strede plytkú oválnu prehlbeninu, azda po nalievaní kovu do formy. Chýbajú bočné švy i zvlnený povrch po odlievaní. Povrch zväčša pokrýva svetlookrová, sčasti opadávajúca patina, v ktorej sa spájajú oxidy medi so zrniečkami pôdy z podložia, známa aj z niektorých nálezov na blízkej Morave (Dobeš a kol. 2019, obr. 12: 8, 9). Na hrane tela klina sa zachoval drobný obtlačok jemnej látky s plátnovou väzbou s rozmermi 0,8 x 0,32 cm (obr. 2). Rozmery: dí. 18,9 cm, š. ostria 5,7 cm, š. tyla 2,4 cm, max. hr. 1,9 cm, hr. tyla 0,9 cm, váha 827,62 g (obr. 3: 1).

Morfologicky i priestorovo najbližší podobný klin (nepublikovaný nález) pochádza z polohy Prekážka na rozhraní katastrov obcí Trstín, Naháč a Horná Krupá, okr. Trnava. Zo Slovenska je podobný nález z Diviakov nad Nitricou, okr. Prievidza (nepublikovaný nález) a Beluše, ktorého zobrazenie v publikácii 


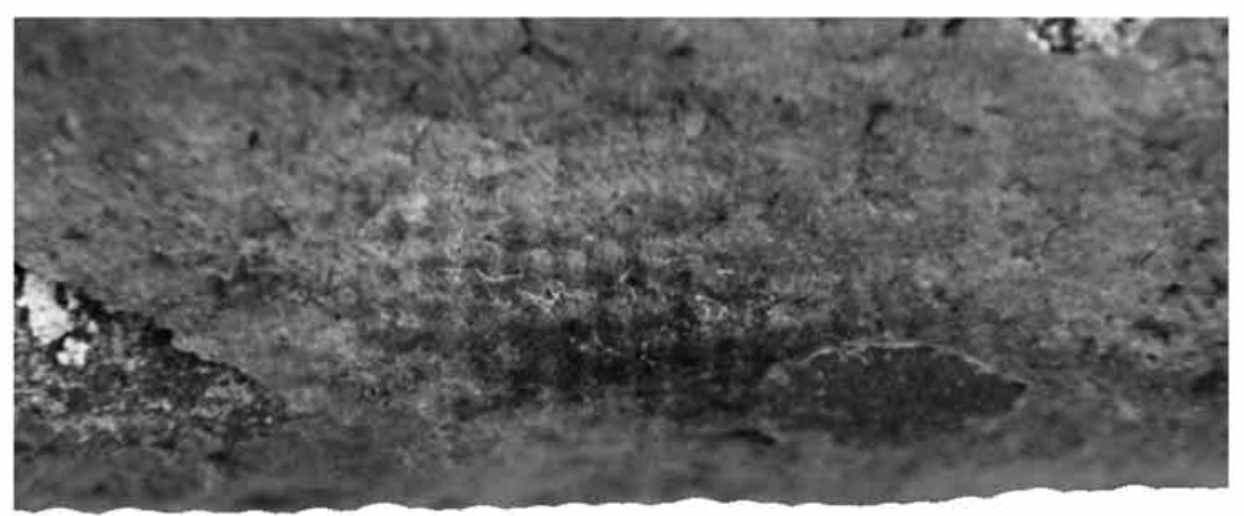

Obr. 2. Chtelnica. Medený klin 1, detail patiny s odtlačkom látky s plátnovou väzbou.

M. Novotnej (1970, 14, tab. 2: 24) sa však odlišuje od predmetu z tej istej lokality, primárne zverejneného M. Pichlerovou (1962, 271, obr. 1). Klin tvarom zodpovedá širšie poňatému typu Szakalhát podla P. Pataya (1984, 24, 25; Novotná 1970, 14), variantu Sárazsadány, s trochu kratším analogickým nálezom z hrobu 21 vo Fényeslitke (Patay 1984, 27, 28, tab. 4: 57), z prostredia bodrogkeresztúrskej kultúry (Patay 1968, 24, obr. 15).

Podla triedenia J. Říhovského (1992, 62-66) spadá medený klin z Chtelnice do skupiny V, pre ktorú sú charakteristické zväčša relatívne vel'ké, ale aj o čosi kratšie nástroje s úzkym telom a plochým pravouhlým prierezom, typ 2 b, variant $\mathrm{Bb}$ (̌̌ihovský 1992, 63, 64). Ich časové zaradenie zodpovedá kultúre Bodrogkeresztúr a s ňou súčasných kultúr tak na Balkáne, ako aj v strednej Európe. V prostredí Malých Karpát nález korešponduje s nájdeným osídlením na víšku Pálenice a Stará Chtelnica. Tomuto datovaniu zodpovedá aj zaradenie podobných nástrojov do I. skupiny medených klinov M. Dobeša v Čechách, na Morave, v Polsku a vo východnej časti Nemecka (Dobeš 1989, 39, 40). M. Dobeš a kol. (2019, 31, obr. 6: 2; 12: 6) podobné nástroje na Morave, nález z Kyjovska sa od predmetu z Chtelnice líši iba prežliabnutými bokmi, kladie do typu Hartberg a na základe analógií ho časovo zarad’uje do obdobia zodpovedajúceho depotu z rakúskeho Stollhoffu (Angeli 1967, 491-496; Dobeš 2013, 37, 38).

Drobný odtlačok jemnej textílie v patine, pravdepodobne s plátnovou väzbou, poukazuje aspoň na čiastočný kontakt kovového nástroja $\mathrm{v}$ zemi s látkou, do ktorej ho azda zabalili pred uložením do zeme. Plochá medená sekerka s odtlačkom látky s plátenou väzbou v koróznych vrstvách, typologicky zodpovedajúca VII. skupine J. Ř́hovského, variant typu Bb, sa našla aj pri archeologickom výskume v násype mohyly 1, v polohe Džbán na lokalite Náměšt na Hané (Šmíd 2005, 102, obr. 6: 3, 4). Autor výskumu predpokladal jej zámerné, votívne uloženie do plášta posmrtného pamätníka kultúry ludu s lievikovitými pohármi. Či zvyšky látky na kline z Chtelnice súviseli s rituálnym uložením, alebo len so snahou o ochranu vzácneho predmetu pri predpokladanom dočasnom uložení do zeme však ostáva iba v rovine úvah.

- Na hrane vrcholovej plošiny Pálenice v nevel'kej vzdialenosti od predchádzajúceho klina, ale bez vzájomného vztahu v zmysle hromadného nálezu, sa našla pomerne malá medená sekerka trojuholníkovitého tvaru s výrazným vejárovite rozšíreným oblúkovým ostrím a iba v náznaku zaoblenými bokmi (obr. 1: 4). Bokorys zodpovedá kopytovitému tvaru s ostrím posunutým k báze. Ostrie je mierne prehnuté bez stôp po pracovnej činnosti. Povrch pokrýva opadávajúca okrová patina. Rozmery: dí. 6,6 cm; š. ostria $3,5 \mathrm{~cm}$; hr. 0,9 cm; š. tyla $1 \mathrm{~cm}$; hr. tyla 0,6 cm; váha $81,06 \mathrm{~g}$ (obr. 3: 6).

Rozmermi i trojuholníkovým pôdorysom sekerka z Chtelnice zodpovedá klinom široko poňatého typu Altheim (Dobeš 1989, 40; 2013, 40, 41; Mayer 1977, 53). Známy je predovšetkým z prostredia eponymnej kultúry Altheim a skupiny Mondsee v alpskej oblasti (Driehaus 1960, tab. 34: 6; Willvonseder 1963-1968), výrazne však odlišný od často do tohto typu zarad’ovaných plochých tenkých sekier obdížnikového tvaru (Kuna 1981, 19-21), pre ktoré sa novšie používa názov typ Vinča (Mayer 1977, 63 a n., tab. 13: 172-181; Žeravica 1993, 57, 58). Na území Madarska sú nálezu z Chtelnice blízke trapézovité sekerky 


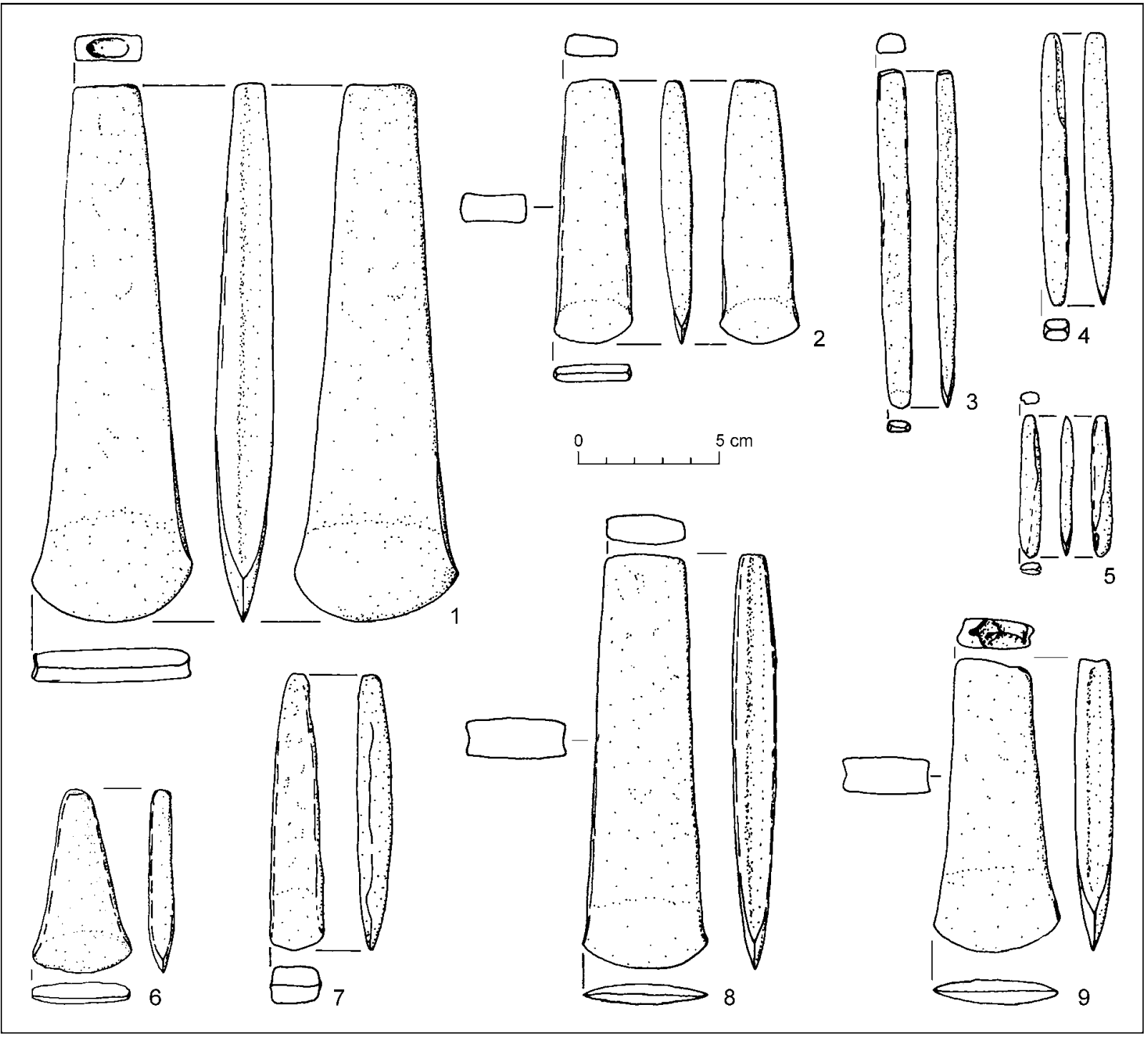

Obr. 3. Medené nástroje. 1, 2, 6 - Chtelnica, poloha Stará Chtelnica a Pálenice; 3, 5, 7 - Dolný Lopašov, poloha Cernik; 4 - Chtelnica, poloha Holý vrch; 8, 9 - Dobrá Voda, poloha Lazy.

s oblúkovým ostrím typu Hajdúszoboszló (Patay 1984, 31, 32, tab. 5: 76-78), ktoré P. Patay (1984, 32) na podklade nálezov $\mathrm{v}$ hrobových celkoch spája s tiszapolgárskou kultúrou a považuje ich za jedny $\mathrm{z}$ najstarších medených nástrojov v Karpatskej kotline. Trapézovité sekerky typu Altheim, vyčleneného podla nálezov z okolia alpských jazier, sú však chronologicky mladšie a zodpovedajú zväčša obdobiu počiatku kultúry ludu s lievikovitými pohármi a skupine Bajč-Retz (Obereder/Pernicka/Ruttkay 1993, 5-9). V takomto prípade by sekerka z vŕšku Pálenice pri Chtelnici časovo spadala do obdobia záverečného vývoja lengyelskej kultúry (tzv. epilengyel), doloženej v tejto oblasti aj črepovým materiálom. M. Dobeš a kol. (2019, 33, obr. 8: 5; 14: 6) však novšie kladie podobné tvary do typu Pölshals a na podklade nálezov v sídliskovom materiáli ich výskyt spája až s kultúrou ludu s mladšou badenskou keramikou, príp. s obdobím mladého eneolitu reprezentovaného jevišovickou či řivnáčskou kultúrou. Podobný tvar sekerky, ale s výrazným pravouhlým prierezom, napr. našli spolu s medeným šidlom pri archeologickom výskume výšinnej opevnenej polohy v Brne, mestskej časti Bosonohy, datovanej sprievodným materiálom do obdobia mladšej jevišovickej kultúry. Z lokality však pochádzali aj fragmenty keramiky Bajč-Retz-Křepice. Autori výskumu pre tento tvar navrhovali vyčlenit samostatný variant Bosonohy základného typu Altheim (Kazdová/Šebela 1999, 190, 192, obr. 2: 12). Sekerka typu Pölshals sa našla aj na výšinnej opevnenej polohe Denemark pri Kutnej Hore v Čechách, kde však jej časové zaradenie do obdobia řivnáčskej kultúry tiež nie je celkom jednoznačné, ale pravdepodobné (Zápotocký/Zápotocká 2008, 254, obr. 130: 2). 
Bez širšie koncipovaného archeologického výskumu na Starej Chtelnici a prilahlých Páleniciach tak zatial' ostáva časové zaradenie tejto trapézovitej sekerky otvorené, od obdobia ludanickej skupiny LgK (s vyššou dávkou pravdepodobnosti) až po záver vývoja badenskej kultúry.

- Z polohy Pálenice či Stará Chtelnica, bez presnejšej lokalizácie (obr. 1: 2), pochádza aj medený klin nevýrazne trapézovitého tvaru so šikmým rovným tylom a mierne rozšíreným oblúkovým ostrím. Priečny prierez tela je obdížnikový, s nevýrazne zaoblenými bokmi, pozdĺžny mierne bikonvexný. Telo pokrýva na povrchu žltohnedá patina pozostávajúca z koróznych vrstiev premiešaných so svetlou zeminou z podložia. Na poškodených miestach presvitá svetlá zelená medenka, ktorá sa neoddeluje od kovu. Povrch je hladký, bez stôp po odlievaní. Rozmery: dí. 9,1 cm; š. ostria 2,7 cm; š. tyla 1,7 cm; max. hrúbka $1 \mathrm{~cm}$; hr. tyla $0,7 \mathrm{~cm}$; váha 132,72 g (obr. 3: 2).

Klin z Chtelnice má blízke analógie v náleze z Pezinka z bývalých kasární Protivzdušnej obrany štátu, dnes Špecializovaného trestného súdu (Farkaš 1997, 9, 12, obr. 2: 1). Možno ho zaradit medzi medené nástroje ešte výrazne ovplyvnené kamennými predlohami. Podla $M$. Dobeša $(1989,39)$ vychádza z typu Pločnik, ktorý bol rozšírený v celej juhovýchodnej Európe (Kuna 1981, 17, 18) a na podklade dížkovo šírkového indexu zodpovedá najskôr variantu Strážnice s pomerne dlhým časovým vývojom od obdobia ludanickej skupiny až po skupinu Bajč-Retz (Dobeš 1989, 41, obr. 1; 2013, 38).

Ďalšie tri zdokumentované medené predmety sa našli už mimo polohy Pálenice a Stará Chtelnica.

- Jedným z nich, z polohy Holý vrch, je dláto s takmer kvadratickým priečnym prierezom, zúženým ostrím, nevýrazne prehnutým tylom a mierne bikonvexným pozdížnym profilom. Pripomína tak staršie kamenné predlohy, predovšetkým malé kopytovité kliny. Liaty kov však umožnil celkové zoštíhlenie nástroja. Kvalitne metalurgicky zvládnutý predmet bez švov a iba s ojedinelým zvlnením povrchu pokrýva žltozelená, miestami sa olupujúca patina. Rozmery: dí. 9,6 cm; pr. 0,9 x 0,9 cm; š. ostria 0,55 cm; váha 51,85 g (obr. 3: 4).

Dláto našli na výraznom vŕšku so strmými svahmi pri vstupe do Chtelnickej doliny, ktorý ju prevyšuje približne o $108 \mathrm{~m}$. Na jeho vrchole, pri kóte 324, sa na prelome 19. a 20. storočia nachádzali role rímsko-katolíckej fary v Dolnom Lopašove (samotná poloha však patrí do katastra obce Chtelnica), na ktorých uskutočnil miestny kaplán a neskôr farár F. Šándorfi dlhotrvajúci archeologický výskum. Z prekopaných kultúrnych jám, okrem zlomkov keramiky, získal aj bohatú kolekciu kamennej brúsenej a štiepanej industrie. Podla odhadu A. Loubala $(1933,594)$ pozostávala asi z 3000 predmetov. Cast’ z nich sa prostredníctvom zbierky P. Jedlicsku dostala do fondov dnešného Západoslovenského múzea v Trnave (Novotný/Fuhrherr 1971, 5, 6, tab. I; II).

Kolekcia je pomerne nesúrodá a obsahuje štiepanú industriu od mladého paleolitu (gravettien?) cez neolit a eneolit, vrátane rozhrania neskorej doby kamennej a staršej doby bronzovej (Bátora 2015, 22) až po novoveké súčasti pušiek s kresadlovým zámkom. Väčšina kamenej brúsenej i štiepanej industrie sa však nevymyká z morfologického rámca charakteristického pre LgK, vrátane jej záverečnej fázy reprezentovanej ludanickou skupinou (Loubal 1934, tab. VII; VIII).

Drobné dlátka so štvoruholníkovým prierezom boli donedávna zastúpené v nálezoch medenej industrie na Slovensku iba sporadicky (Novotná 1970, 67; 1978-1979, 63). S rozšírením detektorov kovov však ich nálezov postupne pribúda. $\mathrm{V}$ okolí Chtelnice sú zastúpené najmenej tromi exemplármi a z Malých Karpát aj ich predpolia boli nedávno zverejnené exempláre z Dolných Orešian, Trnavy a Velkého Grobu (Farkaš 1997, 10-12). Pri náleze z Vel'kého Grobu však pre vysoký obsah cínu $(9,2$ \%) nemožno vylúčit ani jeho zaradenie až do doby bronzovej (Farkaš 1997, 10; LongaueroválLongauer 1997, 19-24).

Predlohy dlát tohto typu sa zvyčajne hladajú na Balkáne (Novotná 1978, 213, 214; Todorova 1981, 23, 24; Vizdal 1977, 92, 114). Analogické predmety známe z juhozápadného Slovenska (Farkaš 1997, 11), z Madarska (Patay 1984, 22) a Moravy (Vaškových 2004, 161, 162) umožňujú spolu s nálezmi z Vel'kých Raškoviec (Vizdal 1977, 92 a 114) ich časové zaradenie zväčša do obdobia starého eneolitu, vrátane jeho druhej polovice, v oblasti Malých Karpát, reprezentovanej pomerne dlhodobým vývojom ludanickej skupiny (Farkaš 1997, 11). Dláto tak zrejme umožňuje spolu s kamennou brúsenou a štiepanou industriou, zväčša chronologicky menej citlivou, zaradit aspoň čast’ vývoja zaujímavého výšinného sídliska na Holom vrchu práve do tohto obdobia.

- Druhé dlátko sa našlo už v katastri Dolného Lopašova, okr. Pieštany na hrane úvozu vedúceho na pomerne rovný kopec Cernik, vo vzdialenosti približne $0,95 \mathrm{~km}$ od Holého vrchu a $2 \mathrm{~km}$ od vrcholu Pálenice (obr. 1: 6). 
Miniatúrne medené dlátko s nepravidelným, skôr oválnym ako štvoruholníkovým prierezom a zaobleným ostrím. Tylo je zahrotené. Na dorzálnej aj bazálne strane nástroja sa zachoval nepravidelný plastický šev po odlievaní. Povrch pokrýva odlupujúca sa hnedo zelená patina. Rozmery: dí. 4,95 cm; max. š. 0,7 cm; max. hr. 0,4 cm; š. ostria 0,55 cm; váha 8,95 g (obr. 3: 5).

- Tretie dlátko nie je možné presne lokalizovat'. Našlo sa bud' na hrebeni Cernika, SSZ od predchádzajúceho nálezu (obr. 1: 7), alebo pri pláži Chtelnickej priehrady, niekde v blízkosti hrádze. ${ }^{1}$ Dlátko je s výrazne predíženým telom nepravidelného obdížnikového prierezu s mierne zaoblenými bokmi, zúženým ostrím a rovným tylom. Povrch je výrazne korodovaný, medeno-červený so zvyškami odpadávajúcej patiny hnedozelenej farby, hladký, bez stôp po odlievaní predmetu. Rozmery: dí. 11,8 cm; pr. $0,6 \times 1 \mathrm{~cm}$; š. ostria $0,55 \mathrm{~cm}$; váha $63,89 \mathrm{~g}$ (obr. 3: 3).

Všetky tri dlátka z Chtelnice a Dolného Lopašova patria v podstate $\mathrm{k}$ jednému typu a zrejme ich tak odliali a používali v časovom úseku starého eneolitu, v období záveru lengyelskej kultúry.

- Posledným zdokumentovaným medeným predmetom z okolia Chtelnice, pri ktorom však nie je isté, či sa našiel pri Chtelnickej vodnej nádrži, alebo na vrchu Cernik (obr. 1: 7), je medený klin mierne trapézovitého tvaru, ktorý ešte zretelne vychádza z kamenných predlôh. Priečny rez má nepravidelný obdížnikový tvar, pozdĺžny zodpovedá nízkym kopytovitým klinom so zníženým tylom a nepravidelným, esovito prehnutým oblúkovým, pracovnou činnostou nepoškodeným ostrím. Na bokoch sa zachovali švy po odlievacej forme. Povrch je medeno-červený so zvyškami opadávajúcej žlto zelenej patiny. Rozmery: dí. 9,8 cm; š. 0,9-2 cm; max. hr. 1,2 cm; š. ostria 1,8 cm; váha 111,2 g (obr. 3: 7).

Jednoduché medené nástroje so zretel’nými väzbami na kamenné predlohy s pomerom dížky $\mathrm{k}$ šírke približne v pomere $5: 1$ sa označujú ako typ Pločnik (Kuna 1981, 17), ktorý bol vo svojich variantoch rozšírený v celej juhovýchodnej Európe. Klin z okolia Chtelnice sa výzorom hlási k archaickým tvarom (Angeli 1967, tab. 2; Dobeš 1989, 39, 40; 2013, 37, 38; Dobeš a kol. 2010, 57-67; Mayer 1977, 50-52, tab. 13: 131-134; Šikulová/Zápotocký 2010, 411, 412, obr. 5: 2, 3, 5). Tvarovo blízky nález z moravských Paršovic (Dobeš a kol. 2019, obr. 5: 5; 12: 4) však kladie M. Dobeš a kol. $(2019,31)$ už do pokročilejšieho typu Stollhoff. Pre svoj archaický výzor by tak klin mohol teoreticky byt๋ zatial jedným z najstarších medených predmetov nájdených v Malých Karpatoch v okolí Chtelnice, azda ešte z obdobia zodpovedajúceho stupňu Lengyel III, Brodzany, hoci celkom nemožno zabúdat ani na pomerne dlhý predpokladaný časový úsek využitia tohto typu medených klinov (Kuna 1981, 17, 18).

Ďalšie dva medené kliny sa našli na okraji obce Dobrá Voda, okr. Trnava, v polohe Lazy. Miesto nálezu sa nachádza približne 4,5 km smerom na západ od masívu Pálenice-Stará Chtelnica, na miernom svahu klesajúcom $\mathrm{k}$ dnes regulovanému potoku Mariáš, na rozhraní záhrad a polí, tesne pri polnej komunikácii v nadmorskej výške okolo 250 m (obr. 1: 8). Údajne sa našli tesne pri sebe a možno ich považovat za hromadný nález. Predstavujú tak prvý doložený depot eneolitických medených predmetov z Malých Karpát, hoci informácie o iných, často pomerne hodnoverné, sú súčastou zberatel'skej mytológie. K nim patria napr. sekeromlaty (vraj typu Handlová) zo Starej Chtelnice, sekeromlat zasunutý do špirálovej náramenice z Horných Orešian, Slepého vrchu, súbor rôznych špirál z jaskyne Dzeravá skala alebo Tmavá skala pri Plaveckom Mikuláši. Bez možnosti preskúmania inak v obci obecne známeho nálezu nie je isté, či predmety zvinuté z hrubších, zväčša plochých drôtov prípadne nepatrili až do mladšej alebo neskorej doby bronzovej, kam ho zväčša kladú aj pôvodné informácie o náleze. Správy o depotoch eneolitickej medenej industrie však pribúdajú aj z iných oblastí Slovenska.

- Klin medený mierne trapézovitého tvaru s rozšíreným rovným oblúkovým ostrím a konkávnymi bokmi, obdížnikovým prierezom a s nevýrazne bikonvexnou bazálnou i dorzálnou stranou (obojstranné prežliabnutie bokov dosahuje približne $0,5 \mathrm{~cm}$ ). Pozdížny rez je mierne bikonvexný, tylo je rovné. Boky a jednu širšiu stenu pokrýva hnedozelená, akoby vyleštená patina, $\mathrm{z}$ druhej opadáva a odhaluje pôvodný hnedočervený povrch. Rozmery: dí. $14,5 \mathrm{~cm}$; š. tyla $2,9 \mathrm{~cm}$; š. ostria $4,3 \mathrm{~cm}$; hr. tyla $0,9 \mathrm{~cm}$; max. hr. 1,6 cm; váha 507,85 g (obr. 3: 8).

- Klin medený mierne trapézovitého tvaru s rozšíreným rovným oblúkovým ostrím a konkávnymi bokmi pri inak obdížnikovom priereze (obojstranné prehnutie dosahuje približne $0,5 \mathrm{~cm}$ ). Pozdĺžny rez je mierne bikonvexný, so zníženým tylom. Tylo je rovné s nepravidelnou prehĺbeninou a jazvou po na-

\footnotetext{
Nálezcovia vzájomne zamieňali miesto nálezu dlátka (obr. 3: 3) a klina (obr. 3: 7).
} 
lievaní kovu do čiastočne stranovo deformovanej formy. Jednu zo širších plôch klina pokrýva dokonalá hnedozelená, akoby vyleštená patina, z druhej sa odlupuje a odhaluje pôvodný medený, hnedočervený povrch. Rozmery: dí. 10,2 cm; š. tyla 2,6 cm; š. ostria $4,4 \mathrm{~cm}$; hr. tyla 1,05 cm; max. hr. 1,35 cm; váha 287,18 g (obr. 3: 9).

Zhodná patina podporuje predpoklad, že obidva kliny boli uložené v rovnakom prostredí, a mohli skutočne tvorit jeden, do zeme zámerne uložený celok. Kliny z Dobrej Vody majú blízku analógiu v nálezoch z Chtelnice (obr. 3: 2) a z Pezinka (Farkaš 1997, 9, 12, obr. 2: 1). Možno ich tak zaradit medzi medené nástroje vychádzajúce z typu Pločnik, ovplyvnené kamennými predlohami (Dobeš 1989, 39). Na podklade dížkovo šírkového indexu zodpovedajú najskôr typu Strážnice s pomerne dlhým časovým vývojom od obdobia ludanickej skupiny až po skupinu Bajč-Retz (Dobeš 1989, 41, obr. 1; 2013, 37, 38) alebo Stollhoff, variantu Hartberg (Mayer 1977, 46 tab. 9: 97-100), azda pretrvávajúceho až po začiatok stredného eneolitu. Ten je v malokarpatskom priestore reprezentovaný bolerázskou skupinou badenskej kultúry. Podobné prežliabnutie bokov ako pri klinoch z Chtelnice je na Morave doložené na nástroji typu Hartberg z Kyjovska (Dobeš a kol. 2019, 32, obr. 6: 2). Technológia výroby medenej industrie, pri ktorej zrejme v tomto období ešte prevládalo odlievanie do "stratenej formy“, umožňovala rôzne variácie na základný prototyp ovplyvnené predovšetkým schopnostami, skúsenostami i možnostami jednotlivých kovolejárov. To sa odzrkadlilo $\mathrm{v}$ istej variabilite nástrojov, často stažujúcej ich zaradenie do jednotlivých typov a variantov, výrazne ovplyvnených subjektívnym pohladom bádatela. Podla novšieho triedenia M. Dobeša a kol. $(2019,32$, obr. 6: 6) by tak kliny z Dobrej Vody boli blízke prechodnému typu Malhostovice.

Obec Dobrá Voda leží v centre mierne zvlnenej Dobrovodskej kotliny obklopenej vrchmi Malých Karpát. So Záhorím a Trnavskou pahorkatinou ju spájajú úzke doliny smerujúce k Dechticiam, Hradištu pod Vrátnom, Brezovej pod Bradlom, či napájajúce sa na Chtelnickú dolinu. Odvodňovaná je riečkou Blava s tromi hlavnými prítokmi (Mariáš, Hlavina, Jaseňový potok). Zo starších zberov a súkromných zbierok, ktorých korene zasahujú prinajmenšom do obdobia pobytu J. Hollého na tunajšej fare, sa dostalo do zbierok dnešného Západoslovenského múzea v Trnave zopár kamenných brúsených nástrojov s prevŕtaným otvorom pre rukovät (Keller 1964, 24; Novotný/Fuhrherr 1971, 44, 54). Na začiatku 21. storočia k nim pribudla v SNM-AM v Bratislave rozsiahla kolekcia kamennej brúsenej, ako aj predovšetkým štiepanej industrie, zozbieraná na poliach v okolí obce i v údolí spájajúcom ju s Chtelnickou dolinou (Farkaš/Plachá 2002, 79). Sprievodný, aj ked’ len drobný keramický materiál umožňuje tunajšie osídlenie zaradit do obdobia od starších malovaných stupňov LgK až po badenskú kultúru. Tomu zodpovedá aj typologická skladba kamennej brúsenej industrie, vrátane početných zlomkov sekeromlatov. Medzi štiepanými nástrojmi sa však objavujú ojedinele aj predmety, ktoré možno azda spájat’ ešte s obdobím mladého paleolitu. Pozornost’ si zaslúži aj informácia tunajších pracovníkov lesnej správy, podla ktorých sa brúsené kamenné nástroje spolu s prepálenou zeminou nachádzali aj vo vrtoch pre stĺpy oplotenia zvernice, ktoré osádzali na hrebeni blízkych vŕškov (Skalky, Malé Skalky). Medené kliny sa tak našli v pomerne intenzívne využívanej uzavretej sídliskovej aglomerácii uprostred Malých Karpát, ktorej atraktivitu predovšetkým pre eneolitické obyvatel'stvo zrejme nemožno vysvetlit len tým, že cez Dobrovodskú kotlinu prechádzalo niekol'ko skôr lokálnych, ako nadregionálnych komunikácií. Kotlina zrejme poskytovala relatívny pocit bezpečia s dostatkom, aj ked' nie celkom ideálnej polnohospodárskej pôdy (rendziny, kambizeme rendzinové, luvizeme modálne a luvizeme pseudoglejové - www.podnemapy.sk). Výhodou však mohli byt’ početné pramene vody (dodnes sa ich tu nachádza 42) a azda aj iné prírodné zdroje (drevo, les na pastvu) a pod. Podla charakteru štiepanej industrie sa táto aspoň sčasti vyrábala priamo na mieste. Či na tento účel boli vhodné aj rohovce z miestnych wettersteinských dolomitov (www.mapserver.geology.sk), zrejme ozrejmí až budúci výskum. Nemožno celkom vylúčit, že prítažlivost’ Dobrovodskej kotliny pre ludí neskorej doby kamennej mohli zvyšovat aj miestne neobvyklé zdroje vody, napr. občasná vyvieračka Pod Bachárkou, pôvodný prameň Blavy, s výdatnostou okolo 120 l/s, vytekajúci z podzemného krasového systému a pôvodne nezamŕzajúci ani za najväčších mrazov. Podla kňaza a historika L. Dedek-Crescensa ${ }^{2}$ sa priamo nad ním na skalnatom brehu nachádzala dnes zničená archeologická lokalita s pravekými nálezmi, ktorú interpretoval ako pohanské obetisko. Azda v minulosti aj valom chránená poloha sa zvyčajne spájala s obdobím mladšej a neskorej doby bronzovej, prípadne staršej

\footnotetext{
2 Za informáciu d’akujeme dr. E. Studeníkovej, CSc.
} 
doby železnej ${ }^{3}$ Podla pomerne spolahlivých informácií aspoň ojedinelé nálezy z doby bronzovej pochádzajú aj z polohy Pálenice a Stará Chtelnica, doložený je však iba listovitý hrot oštepu či kopije. Informácie o nálezoch z polohy Skalky a Vel'ká či Malá Klenová, vrátane údajne najmenej desiatich depotov bronzov sa zatial' pohybujú len v rovine viac či menej pravdepodobných informácií, azda ovplyvnených aj tzv. „hl’adačsko-zberatel’skou (mrcasníckou) latinou“. V každom prípade však okolie Chtelnice bolo v nezanedbatel'nej miere osídlené tak v eneolite, ked' sa však doklady miestnej metalurgie prejavujú zväčša iným spôsobom (Farkaš/Gregor 2013, 29 a n.; Nevizánsky/Šalkovský/Zachar 2017, 41-44), ako aj v dobe bronzovej. To spolu s výskytom kovovej industrie, zatial' však bez dokladov jej miestnej výroby, neulahčuje časové zaradenie chtelnického medeného ingotu chemickým zložením najskôr zodpovedajúceho využitiu chalkopyritickej rudy.

\section{ZÁVER}

Súčasné poznatky zatial’ neumožňujú jednoznačné časové zaradenie neobvyklého medeného ingotu nájdeného v Malých Karpatoch v blízkosti obce Chtelnica, okr. Pieštany. Poukazujú však na pomerne intenzívne osídlenie tunajšieho horského prostredia s doposial' s dvomi doloženými maximami. Jedným z nich je obdobie od prelomu neolitu a eneolitu až po začiatok vývoja badenskej kultúry a druhým mladšia až neskorá doba bronzová. Obidva časové úseky sa vyznačujú rozvinutou metalurgiou kovov. Či opakovaný tunajší posun do horských oblastí súvisel s predpokladanými klimatickými zmenami, pri ktorých sa dostávali do popredia dostatočné zásoby vody, využívaním iných miestnych prírodných zdrojov, hladaním bezpečia, kontrolou prechodov cez pohorie, ich kombináciou, alebo celkom inými príčinami, azda ukáže až budúci výskum.

\section{LITERATÚRA}

Angeli 1967

Bátora 2015

Dobeš 1989

Dobeš 2013

Dobeš a kol. 2010

Dobeš a kol. 2019

Driehaus 1960

Farkaš 1997

Farkaš, v tlači

Farkaš/Gregor 2013

Farkaš/Plachá 2002

Habovštiak 1972
W. Angeli: Der Depotfund von Stollhof. Annalen des Naturhistorischen Museums in Wien 70, 1967, 491-496.

J. Bátora: Silicitové dýky z Plaveckého Podhradia a Dolného Lopašova. In: J. Bartík (ed.): Zborník na pamiatku Jozefa Paulíka. Zborník SNM. Archeológia. Supplementum 9. Štúdie. Bratislava 2015, 21-27.

M. Dobeš: Zu den äneolithischen Kupferflachbeilen in Mähren, Böhmen, Polen und in der DDR. Praehistorica 15/16, 1989, 39-48.

M. Dobeš: Měd’ v eneolitických Čechách. Dissertationes Archaeologicae Brunenses/Praguense 16. Praha 2013.

M. Dobeš/P. Fojtík/M. Kalábek/P. Kalábková/J. Peška: K počátkům výskytu měděné industrie na Moravě, sekerky z Hulína-Pravčič a Laškova-Kandie. Přehled výzkumů 51, 2010, 57-68.

M. Dobeš/M. Fikrle/A. Drechsler/K. Faltýnek/P. Fojtík/J. Halama/Z. Jarůšková/ M. Kalábek/J. Langová/Z. Schenk/S. Španihel/J. Peška: Eneolitická měděná industrie na Moravě. Nové a staronové nálezy ve světle stávajících poznatků o vývoji středoevropské metalurgie. Památky archeologické 110, 2019, 5-58.

J. Driehaus: Die Altheimer Gruppe und das Jungneolithikum in Mitteleuropa. Mainz 1960.

Z. Farkaš: Ojedinelé nálezy medenej industrie na juhozápadnom Slovensku. Zborník SNM 91. Archeológia 7, 1997, 9-17.

Z. Farkaš: Medený ingot z Chtelnice. In: Zborník k jubileu Jozefa Bátoru, v tlači.

Z. Farkaš/M. Gregor: Doklady metalurgie kovov na západnom Slovensku na prelome starého a stredného eneolitu. In: I. Cheben/M. Soják (ed.): Otázky neolitu a eneolitu našich krajín 2010. Nitra 2013, 29-52.

Z. Farkaš/V. Plachá: Neolitické a eneolitické nálezy z Malých Karpát a otázka výšinných sídlisk. In: I. Cheben/I. Kuzma (ed.): Otázky neolitu a eneolitu našich krajín 2000. Nitra 2002, 73-89.

A. Habovštiak: Stredoveké hrádky na Slovensku. Vlastivedný časopis 21, 1972, $2-8$.

3 Podla dnes už tažko overitelných informácií miestnych obyvatelov sa tu bronzové predmety nachádzali aj pri výstavbe vodárne, zachytávajúcej spod skaly vytekajúci prameň. 
Janšák 1930

Janšák 1935

Kazdová/Šebela 1999

Keller 1964

Klčo 1998

Könyöki 1905

Kuna 1981

Longauerová/Longauer 1997

Loubal 1933

Loubal 1934

Mayer 1977

Nevizánsky/Šalkovský/Zachar 2017

Novák 1984

Novotná 1970

Novotná 1978

Novotná 1978-1979

Novotný/Fuhrherr 1971

Obereder/Pernicka/Ruttkay 1993

Patay 1968

Patay 1984

Pichlerová 1962

Ř́hovský 1992

Sándorfi 1895

Šikulová/Zápotocký 2010

Šmíd 2005

Todorova 1981

Vaškových 2004

Vizdal 1977

Willvonseder 1963-1968

Zápotocký/Zápotocká 2008

Žeravica 1993

\section{Internetové zdroje:}

www.mapserver.geology.sk www.podnemapy.sk
Š. Janšák: Staré osídlenie Slovenska. A. Sídlištia na pieskových dunách rieky Moravy. B. Hradiská v hornom teréne. C. Drobnejšie hradiská a sídliská. In: Sborník Muzeálnej slovenskej spoločnosti 24, 1930, 1-67.

Š. Janšák: Staré osídlenie Slovenska. Sborník Muzeálnej slovenskej spoločnosti 29, 1935, 15-51.

E. Kazdová/L. Šebela: Eneolitické osídlení hradiska u Brna-Bosonoh (okr. Brno-město). Pravěk Nová řada 9, 1999, 181-195.

I. Keller: Cesta cez Malé Karpaty vo svetle nálezov kamenných nástrojov. Zprávy Západoslovenského múzea v Trnave 4, 1964, 21-35.

M. Klčo: Praveké a stredoveké osídlenie obce. In: J. Polakovič (ed.): História Chtelnice. 790 rokov. 1208-1998. Chtelnica 1998, 5-12.

J. Könyöki: A középkori várak. Különös tekintettel Magyarországra. Budapest 1905.

M. Kuna: Zur neolithischen und äneolithischen Kupferverarbeitung im Gebiet Jugoslawiens. Godišnjak (Sarajevo) 19, 1981, 13-81.

M. Longauerová/S. Longauer: Štruktúrna a chemická analýza archeologických predmetov na báze medi. Zborník SNM 91. Archeológia 7, 1997, 19-24.

A. Loubal: Neolit a eneolit v Jedlicskovej zbierke. Kultúra 5, 1933, 589-599, 773-781.

A. Loubal: Neolit a eneolit v Jedlicskovej sbierke MSSV. Kultúra 6, 1934, 472-476.

E. F. Mayer: Die Äxte und Beile in Österreich. Prähistorische Bronzefunde IX/9. München 1977.

G. Nevizánsky/P. Šalkovský/T. Zachar: Archeologický výskum v Slovenskom Pravne. Príspevok k poznaniu metalurgie medi v období eneolitu. Zborník SNM. Kmetianum 14, 2017, 37-47.

P. Novák: Záchranný výskum na stavbě přehrady v Chtelnici. AVANS 1983, 1984, 161-163.

M. Novotná: Die Äxte und Beile in der Slowakei. Prähistorische Bronzefunde IX/3. München 1970.

M. Novotná: Anfänge der Metallurgie in der Slowakei und die Beziehungen zum Ostbalkan. Studia praehistorica 1-2, 1978, 212-217.

M. Novotná: Praveká metalurgia mede a bronzu na Slovensku. Historica 29-30. Zborník Filozofickej fakulty Univerzity Komenského, 1978-1979, 59-71.

B. Novotný/V. Fuhrherr: Katalóg archeologickej zbierky Západoslovenského múzea v Trnave. Bratislava 1971.

J. Obereder/E. Pernicka/E. Ruttkay: Die Metallfunde und die Metallurgie der kupferzeitliche Mondseegruppe. Ein Vorbericht. Archäologie Österreichs 4/2, 1993, 5-9. P. Patay: A fényeslitkei rézkori temető. A Nyíregházi Jósa András múzeum évkönyve 11, 1968, 15-62.

P. Patay: Kupferzeitliche Meißel, Beile und Äxte in Ungarn. Prähistorische Bronzefunde IX/15. München 1984.

M. Pichlerová: Nález medenej sekerky v Beluši. Študijné zvesti Aú SAV 9, 1962, 271. J. ̌́íhovský: Die Äxte, Beile, Meißel und Hämmer in Mähren. Prähistorische Bronzefunde IX/3. Stuttgart 1992.

N. Sándorfi: Pusztavesi östelep Nyitramegyében. Archaeologiai értesitő 15, 1895, 282. V. Šikulová/M. Zápotocký: Raně eneolitický měděný pektorál z vrchu Kotouče u Štramberka. Archeologické rozhledy 62, 2010, 395-428.

M. Šmíd: Výzkum mohylového pohřebiště v poloze „Džbán“ u Náměště na Hané, okr. Olomouc. Pravěk Nová řada 13, 2003, 2005, 91-112.

H. Todorova: Die kupferzeitlichen Äxte und Beile in Bulgarien. Prähistorische Bronzefunde IX/14. München 1981.

M. Vaškových: Měděné předměty z Velehradu a Sušic-Teplic, okr. Uherské Hradiště. In: E. Kazdová/Z. Měřínský/K. Šabatová (ed.): K poctě Vladimíru Podborskému. Brno 2004, 161-165.

J. Vizdal: Tiszapolgárske pohrebisko vo Vel'kých Raškovciach. Košice 1977.

K. Willvonseder: Die jungsteinzeitlichen Pfahlbauten des Attersees in Oberösterreich. Mitteilungen der Prähistorischen Kommission 11/12. Wien 1963-1968.

M. Zápotocký/M. Zápotocká: Kutná Hora-Denemark. Hradiště řionáčské kultury (ca 3000-2800 př. Kr.). Památky archeologické. Supplementum 18. Praha 2008.

Z. Žeravica: Äxte und Beile aus Dalmatien und anderen Teilen Kroatiens, Montenegro, Bosnien und Herzegowina. Prähistorische Bronzefunde IX/18. Stuttgart 1993. 


\title{
Eneolithic copper industry from the vicinity of Chtelnica
}

\author{
Z de něk Farka š
}

Summary

Around 2010, workers of the Štátne lesy company found a copper ingot in shape of an incomplete cone in western Slovakia, in the residential area of Chtelnica, Pieštany district (Fig. 1). The compact lump of melted material with porous structure preserved the internal shape of the thermic device with a flat bottom and conically widening walls (Farkaš, in print). The unusual shape of the raw material lump and unknown find context do not allow definite chronological classification of the item, although most indices suggest its younger, possibly post-prehistoric origin. Employees of SNM, Archaeological Museum in Bratislava, managed to document nine eneolithic copper tools - 6 wedges and 3 chisels (Fig. 1;3) - in the attempt to obtain as much data as possible on the location of its discovery from the areas of the neighbouring villages of Chtelnica, Dolný Lopašov and Dobrá Voda, Pieštany and Trnava districts. They were all discovered in the part of the Little Carpathians currently covered with forest. Three of them come from the previously unstudied upland site from the Lengyel culture period at Pálenica and Stará Chtelnica (the area of Chtelnica) mainly corresponding with the development of the Ludanice and Bajč-Retz groups (Fig. 3: 1, 2, 6). On the surface of one wedge, an imprint of cloth with tabby weave was preserved in patina (Fig. 3: 1; 3). It was probably wrapped in the cloth before it was deposited in the ground. One of the chisels was found on the dominant site of Holý vrch, next to the entrance to the Chtelnická dolina valley with documented finds mainly from the eneolithic groups of the Lengyel culture to the beginning of the Bronze Age (Fig. 3: 4). Two small axes, originally from the hoard found in the Dobrovodská kotlina basin (area of the village of Dobrá Voda), come from an enclosed settlement area with numerous finds of chipped and polished lithic industry from the period of the Ludanice group - Baden culture (Fig. 3: 8, 9). Other two tools were found on the large hill of Cernik in the area of Dolný Lopašov without any previously documented finds; the exact origin of the last one is not clear. When searching for the contexts to the lump of copper raw material, a considerably intense settlement of the local mountainous environment with two previously detected maximums was accidentally documented. One of the maximums is the period from the turn of the Neolithic and Eneolithic to the Baden culture and the second one is the Late/Final Bronze Age. Both periods are typical with developed metallurgy. Whether the repeated local move to the mountainous areas was associated with the supposed climate changes making sufficient water sources more important, use of other local natural sources, search for security, control of passes through the mountains, their combination or totally different reasons, might be shown by further investigation.

Fig. 1. Map of the Little Carpathians near Chtelnica. 1 - Pálenice site, the location of discovery of the copper ingot; 2 - Stará Chtelnica and Pálenice, assumed extent of the eneolithic settlement; 2-8 - locations of discoveries of eneolithic copper industry; 2-5 - area of the village of Chtelnica; 6, 7 - area of the village of Dolný Lopašov; 8 - village of Dobrá Voda (https://mapy.hiking.sk).

Fig. 2. Chtelnica. Copper wedge no. 1, detail of patina with impression of cloth with tabby weave.

Fig. 3. Copper tools. 1, 2, 6-Chtelnica, Stará Chtelnica and Pálenice sites; 3, 5, 7 - Dolný Lopašov, Cernik site; 4 - Chtelnica, Holý vrch site; 8, 9 - Dobrá Voda, Lazy site.

PhDr. Zdeněk Farkaš, PhD.

SNM, Archeologické múzeum Žižkova 12

SK - 81436 Bratislava

farkaszdeno@zoznam.sk 